\title{
A Study of Designing a Final Achievement Test for English Pronunciation Course
}

\author{
Buhan Pan \\ School of Foreign Languages \\ Huazhong Agricultural University \\ Wuhan 430070, Hubei, China \\ panbuhan@163.com
}

\begin{abstract}
This study intends to design a final achievement test for an introductory English pronunciation course for English majors in Mainland China. The paper firstly clarifies contexts, purposes and learning targets of the test. Then the assessment methods are justified with regard to validity, reliability, practicality and washback. The paper concludes with a discussion of the potential impacts the test may bring.
\end{abstract}

Keywords-achievement test; English pronunciation; assessment; washback

\section{INTRODUCTION}

According to the university curriculum in Mainland China, English majors should take a required course of English pronunciation in the very first semester of their undergraduate studies. As to non-English majors, they don't have this required course, and chances for them to take it as an elective are very small. Owing to this little weight in educational curriculum and the practice-oriented nature of the course, teachers fail to pay enough attention to English pronunciation teaching for a very long time. As to the assessment of English pronunciation, relatively few researches have been done in the field. This paper will focus on designing a final achievement test for an introductory English pronunciation course, hoping that the test will not only provide valid and reliable evaluation of students' learning, but also create beneficial washback for students' future learning in pronunciation and oral English.

\section{LITERATURE REVIEW}

Learning how to produce sounds is the first step of learning any language. Its importance has long been admitted by many linguists. Saussure [1] points out that speech sounds are tools for communication, and meanings rely on sounds for existence. Gimson [2] believes that success in learning a language embraces almost $100 \%$ mastery of its pronunciation, $50 \%$ to $90 \%$ of its grammar, and only $1 \%$ of its vocabulary. The importance of pronunciation is obvious in nature, but in practice pronunciation is usually be neglected.

The testing of English pronunciation occurs within some preliminary oral tests, and sometimes pronunciation can be viewed as part of oral ability. Thus the testing of pronunciation may encounter some similar problems of assessing oral ability. One problem is about the test administration. Pronunciation exams are often administered with large amount of time and low efficiency [3]. Another crucial problem concerns with validity and reliability of testing. Whether we can obtain valid and reliable scoring is the key issue in oral exams [4].

With the development of English pronunciation teaching, McNerne and Mendelsoh [5] claimed that we should place high priority on intelligibility and accuracy, but accent and standard second. That is to say, 'suprasegmentals' are more important than segmentals in teaching English pronunciation. Clennell [6] argues that we should pay more attention to 'pragmatic value' and 'communicative functions' when learning English pronunciation. In other words, we should teach and test pronunciation in context, and 'contextualization' should become the major principle in test design [7].

With the above belief, more and more 'communicative interactions' are introduced in oral tests. However, recent studies have raised doubt on their validity in reflecting situations in real life. McNamara [8] calls for a wider social perspective to be taken into consideration when assessing 'interactions'; Field [9] rethinks the importance of 'intelligibility' and finds that what is intelligible to test takers of the same cultural background may be less so for examiners.

\section{CONTEXTS}

\section{A. Teaching Context}

The instruction of the English pronunciation course is arranged by the Department of Foreign Languages in Huazhong Agricultural University. The course is delivered by an instructor who is under the direct supervision by the head of English major division. The textbook used for this course is $A$ Handbook of English Pronunciation Exercises for First-year College Students [10]. The instructor is mainly responsible for lecturing as well as designing and administering the final achievement test. The instructor will report regularly to the head for approvals on some documents such as teaching plans, progress reports and test papers.

With respect to the physical setting, all the sessions of the course are arranged in language labs of the university. Equipment used in the lab includes desks, chairs, computers, tape recorders and a learning platform system. Teachers should be familiar with operating all the equipment in the lab. There are two technicians who are available in normal working hours, and their job is to facilitate teaching by solving the problems caused by the equipment. 


\section{B. Learning Context}

As to students participating in the course, they should also be familiar with the equipment in the lab. They will use earphones and microphones to communicate with the instructor in class. They can also use the learning platform system and tape recorders for self-assess learning after class. The labs do not provide English or bilingual dictionaries, so students should bring dictionaries to the lab if necessary. Textbook is required for this practice-oriented course, and students should use it under the instructor's guidance. The class size of the course is about 30 students, and each session of the course lasts for one and half hour. Within each session, the instructor tries to keep a balance in equal opportunity for every student. Of course, students should also compete for opportunities to practice their pronunciation.

\section{Description of Test Takers' Characteristics}

Test taker's characteristics are factors that may influence the teaching and learning contexts. For the final achievement exam, test takers are English majors who take this required course in the first year. We can briefly analyze their characteristics from the following two aspects:

1) Personal Characteristics: Test takers are undergraduate students in Huazhong Agricultural University. They are freshmen English majors, and are around 18 years of age. About two third of the students in each class are females. The majority of the students are from rural areas of Mainland China. Most are interested in English, but their language proficiency is generally unsatisfactory. In introductory courses like English pronunciation, they tend to show great enthusiasm and eagerness to learn well.

2) Topical Knowledge: In general, students have obtained enough academic knowledge for undergraduate studies. However, in the field of phonetics, they are lacking in formal and systematic training. Many concepts of the course are new to the students. As to the final achievement test, students will be very familiar with different task types, since they are practiced throughout the whole course. Some tasks may concern topical knowledge of campus life which students are familiar with.

\section{Purposes Of THE TEST}

This is a relatively low-stakes test which is used as a final exam of the course. One of the major purposes of the test is to assess students' mastery of some basic knowledge in phonetics which may include English phonemes, intonation, linking, stress and rhythm. The test is used to determine whether a student has satisfactorily achieved the learning targets listed in the course syllabus. Since the course is required for English majors, students have to pass the exam in order to win credits. If they fail, they will retake the exam. If they fail again, they will not get credits and have to retake the course.

Besides the above decisions made on students' achievement and improvement, results of the test can also provide some valuable information for teaching. Since the tasks used in the test cover a wide range of units taught in the textbook, students' performances in different sections of the test may well illustrate and determine what units of the textbook have been effectively taught, and what units may require improvement in the future teaching. For course designers, results can also be used for research purposes. For example, to compare the results with previous years' can help designers to tailor the course more closely to the needs of students.

Another purpose of the test is to provide feedback to students for their future learning. The English pronunciation course lasts for only one semester in the first year, but the learning of pronunciation does not end. In fact, students should continue to apply the pronunciation knowledge into oral practice so as to stabilize and improve their phonetic ability. The final achievement test will include a marking sheet for each student. After the announcement of results, students will get a copy of their own marking sheet with grading criteria to see how teachers mark their performances and what their weak points of knowledge in English pronunciation are. In this way, the final pronunciation exam becomes a guide and a new starting point for the future learning.

\section{LEARNING TARGETS OF THE TEST}

The learning targets of the course are clearly listed in the course syllabus and the teaching plan. However, not all the targets will be assessed in the final pronunciation test, certain learning targets will be assessed through some other tasks during the whole semester. Since the final exam is in an oral form, it surely cannot test students' listening ability to discriminate different speech sounds. Even within the learning targets of testing, some targets may be assessed indirectly or with little weight. Still, we can summarize four major and obvious learning targets as follows:

- Students can produce each English phoneme correctly, and be good at imitating and discriminating speech sounds.

- Students understand basic rules of word stress and sentence stress, and can use them correctly in real speeches.

- $\quad$ Students have some basic knowledge of linking, weak forms, and rhythms, and can use them properly in connected speeches.

- Students understand the structure and functions of English intonations, and can apply them into real communication.

\section{Methods Of THE TEST}

\section{A. What Methods are and Reasons for Choosing}

The general format of the test is a direct face-to-face interview. Each interview is processed between one test-taker and two examiners. The student is asked to read aloud most test items on the test paper, and will also be asked to make a short speech. The test consists of six parts: vowels, consonants, linking, stress, passage reading and expressing opinions. To be specific with each part of the test, methods used are reading words, reading phrases, reading sentences, reading passages and impromptu speech. In sum, reading aloud and making a speech are methods used in the test. The reasons for using these methods lie in two aspects. Firstly, reading and speaking are 
most direct and effective ways to see whether a student can produce sounds correctly and fluently. Secondly, the total course assessment is determined by several tasks or exams, and the weight of final achievement test is $50 \%$. The test cannot be used to check the fulfillment of all the learning targets, and we should not introduce too many methods in a six-minute oral test. In order to facilitate administration of the test, reading aloud and making a speech are chosen. Thirdly, the methods well match the purposes of testing and best assess the learning targets, which will be discussed in the following two subsections.

\section{B. How Methods Match Purposes of Assessment}

Purposes of assessment deal with decision making. Reading aloud and making a speech are methods teachers can rely on, because they place emphasis on the practice of using sounds. The ultimate goal of learning English pronunciation is to speak the language correctly and beautifully, so understanding rules and distinguishing sounds are not far from enough. The methods can also provide direct and clear feedback for teaching and learning. For example, if many students fail in using the rising intonation properly, the teacher may have to review his or her teaching of intonation. If a student is confused with word stresses when reading passages, he or she will soon reflect on their mistakes and try to find out reasons so as to improve learning.

\section{How Methods Assess Learning Targets}

In the section of Learning Targets of the Test, a summary of four targets is provided. If we compare these targets with methods used in the test, we can find that they are closely related. Reading words is used to find out whether students can articulate different vowels and consonants in a correct way (Target 1). Reading phrases focuses on the mastery of three kinds of linking (Target 3). Reading sentences has something to do with the uses of stress and intonation (Target $2 \& 4$ ). Passage reading and impromptu speech used in Part V and Part VI of the test are very comprehensive methods aiming at four learning targets altogether. They can be used to test students' overall ability of English pronunciation in a natural way.

\section{USEFULNESS OF THE TEST}

In order to describe qualities of language tests in a balanced way, Bachman and Palmer [11] propose a concept of 'usefulness' which includes six components: reliability, construct validity, authenticity, interactiveness, impact and practicality. Here we will discuss three of the components and the test's washback effects so as to deepen our understanding of the pros and cons of the methods used in the test.

\section{A. Validity}

Sometimes we can simply understand validity as to what extent tests assess what test designers want to assess [3]. Here, we can discuss the validity of the test from two aspects: content validity and construct validity. Content validity has something to do with the content relevance and coverage [12], thus we should check whether the test is directly linked to the learning targets in the syllabus. We have done this analysis in the above section Methods of the Test showing how different methods fulfill the purposes and learning targets of the test. Besides, we can add two points as evidence for content validity. First, the test items used in the test are typical examples of phonetic applications. They reflect the key points in learning, and students are supposed to master them well. Second, the test has avoided direct testing of some difficult skills in English pronunciation, such as sound assimilation and weak forms. On the whole, the test is moderate in difficulty and will be suitable for first-year English majors.

As to construct validity, I tend to design the test based on a balanced approach between the traditional ways of testing and 'testing pronunciation in context' [11]. That is to say, on the one hand, 'pragmatic value' and 'communicative functions' [6] are emphasized in the use of assessment methods such as passage reading and impromptu speech which occupy $60 \%$ of the testing weight. On the other hand, testing English phonemes by reading singular words is not omitted. Testing pronunciation is different from testing oral English, and we cannot simply change the test into an oral exam. In a sense, the test is designed with a balance between 'traditional' and 'modern' way of testing.

\section{B. Reliability}

Reliability is the degree of accuracy of measurement. In assessment of pronunciation, it concerns the consistency of scoring. In order to achieve this consistency, the test has been designed with clear assessment criteria and a detailed plan of administration. Within each exam room, two examiners are assigned. Since the process of each interview is mainly an oral presentation from a test-taker, two examiners will both assess the student's performance. The student's final score in the test is an average mark from the two markers. The day before the test administration, all the examiners will be invited to attend a training session for marking. During the meeting, examiners should learn and become familiar with assessment criteria for different parts of the test. Markers should especially unify their understanding of grading criteria in Part V \& VI of the test. Two substitute examiners are also be invited to attend the meeting in case of emergency on the day of test administration.

\section{Practicality}

The test will take a relatively long time for examiners to mark students' performances in their responsible test room. Take English majors of grade 2013 as an example, the total 152 students will be assigned to five test rooms with two teachers in each, and each test room will assess about 30 students. If each student needs roughly six minutes to finish his or her tasks, the whole test will usually last for more than three hours. With the detailed marking items, it also becomes a tough test for challenging teachers' patience and physical health. However, additional teachers to assess English pronunciation are not easily feasible. Since the test is conducted in the form of faceto-face interview and can be processed very easily, it does not rely much on the equipment, thus the cost of the test is relatively low. Therefore, although the test will take much time and energy on teachers, hard working in scoring is worthwhile to give reliable feedbacks for both teachers and students.

\section{Washback}

Bachman and Palmer [11] define washback as the effects of language tests on micro-levels of language teaching and learning. In order to achieve beneficial washback from testing, 
Hughes [4] proposes eight suggestions in her book. If we use these suggestions as criteria in assessing our methods used in the test, we may get the following ideas of the test:

- Direct testing of English pronunciation is a good thing, for it can give an incentive for students to learn.

- Our test includes a wider range of tasks assessing different aspects of English pronunciation, which will arouse a wider range of washback effects.

- Our test sets up clear marking criteria which will motivate students to achieve the level of the criteria.

- Hughes [4] believes that achievement tests should be based on objectives rather than teaching and textbook content. Our test is closely related to learning targets in the syllabus, but also draws a lot of materials from the textbook. In order to achieve positive washback, maybe we should use some new and typical examples beyond textbooks as test items.

- In order to realize potential washback effects from the test, it should be known and understood by students. However, we should also be aware of negative washback of testing. For example, our test does not cover the direct testing of weak forms. If its sample items are made available to students at very early stage of the semester, students may ignore the importance of weak forms when learning. Therefore, detailed introduction of the test should be made at proper stage of the semester for the preparation of final exam.

- Another thing needs to be mentioned here is the use of marking sheet as feedback for students' future learning. Though students may get assessment criteria for reviewing their marking sheet, teachers should also help students to understand the criteria accurately and help them analyze their marking sheets. In this way, beneficial washback effects will be promoted.

\section{IMPACTS OF THE TEST}

Tests may impose influences on individuals, educational system and society at large. The achievement test we design here for an English pronunciation course is not a public exam but a relatively low-stakes test. Hence, decisions made by the results of the test are mainly used to support teaching and learning. So, if we only focus on discussing the test's potential impacts on the learning of students, we may get the following ideas about impacts:

- Students may have positive feelings towards the test, because the test content follows closely the learning targets stated in the syllabus. Teachers may also respond positively to this kind of test, since some test tasks may already be emphasized in teaching.

- The content relevance of the test will motivate students to learn attentively through daily learning activities, because students understand that what they learn daily will definitely be assessed in the future exam. This is a beneficial washback effect to both the learners and the instruction [12].
- In order to better understand test impacts, we can ask test takers to comment on the fairness of the test. In this way, test designers can get valuable feedback from students for future revision.

\section{CONCLUSION}

This project intends to design a final achievement test for an English pronunciation course. The outcome includes a sample test paper and its marking sheet. In summary, the development of the test undergoes a three-step process. Before writing test papers, you should be very clear about the area or the subject you want to assess and do some literature reviews to support your idea of test designing in the area. You should also be familiar with the contexts of testing, establish the learning targets and define the purposes of your assessment. During the designing period, you should justify the use of assessment methods in your test. The test methods are usually discussed with regard to validity, reliability, practicality and washback. After finishing the test design, you could also consider the potential impacts the test may bring. The whole process of developing a test is a process of fulfilling conditions set by relevant factors in testing.

\section{REFERENCES}

[1] F. D. Saussure, “Course in General Linguistics,” R. Harris Trans. Great Britain: Gerald Duckworth Co. Ltd, 1983.

[2] A. C. Gimson, An Introduction to the Pronunciation of English, 3rd ed.. London: Edward Arnold, 1980.

[3] R. Liu and B. Han, Language Testing and its Methods. Beijing: Foreign Language Teaching and Research Press, 2000.

[4] A. Hughes, Testing for Language Teachers. Cambridge: Cambridge University Press, 2003.

[5] M. McNerney and D. Mendelsohn, "Suprasegmentals in the Pronunciation Class: Setting Priorities," In Teaching American Pronunciation, P. Avery and S. Ehrlich, Eds., Oxford: Oxford University Press, 1992.

[6] C. Clennell, "Raising the Pedagogic Status of Discourse Intonation Teaching,” ELT Journal, vol. 2, 1997, pp. 117-125.

[7] B. Bradford, Intonation in Context. Cambridge: Cambridge University Press, 1988.

[8] T. F. McNamara, “'Interaction' in second language performance assessment: whose performance?” Applied Linguistics, vol. 18, 1997, pp. 446-466.

[9] J. Field, “The fuzzy notion of 'intelligibility': a headache for pronunciation teachers and oral testers," IATEFL Special Interest Groups Newsletter in memory of Gillian Porter Ladousse, Spring 2003.

[10] G. Zhang, A Handbook of English Pronunciation Exercises for First-year College Students, 2nd ed.. Beijing: Foreign Language Teaching and Research Press, 2006.

[11] L. F. Bachman and A. S. Palmer, Language Testing in Practice. Oxford: Oxford University Press, 1996.

[12] L. F. Bachman, Fundamental Considerations in Language Testing. Oxford: Oxford University Press, 1990. 